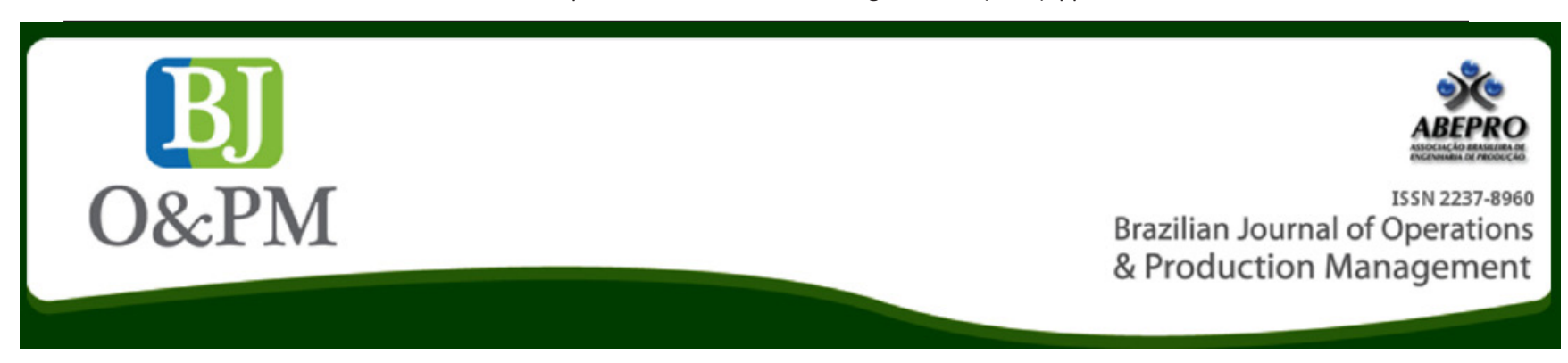

\title{
BUSINESS PROCESS MANAGEMENT NOTATION FOR A COSTING MODEL CONCEPTION
}

Marcelo Bernardino Araújo; Bruno Amado Rodrigues Filho; Rodrigo Franco Gonçalves ${ }^{a}$

a Paulista University (UNIP) - São Paulo, SP, Brasil

\section{ABSTRACT}

Purpose - Aims to show the importance of business processes modeling as a precondition for information system design. Although many managers worry the entity's expenses, some are unaware of the processes and procedures adopted by his subordinates. Searching is to calculate spending on each step to a proper business process management.

Design/methodology/approach - It shows the concepts of Activity-Based Costing (ABC) and its update, the TDABC (TimeDriven Activity-Based Costing), to support the development of a costing system for public universities.

Findings - It can be concluded that public processes implemented in public services are both complex and bureaucratic, mainly due to regulations. The bidding procedure of acquisition materials or services demand eight sectors activities.

Research limitations/implications - The contribution of this study is to present how the business process modeling should not be applied to public service for the optimization of resources. This research presents the usual flow of bids, but in practice there is some variation.

Practical implications - The article provides a starting point for process redesign and complex and inefficient procedures in order to reduce costs.

Originality/value - Although the cost accounting to present different types of costing methods, managers need to know and criticize the existing business processes.

Keywords: business modeling, costing, business processes management, BPMN, TDABC. 


\section{INTRODUCTION}

The responsibility of a public university is not only teaching, but also provide extension activities and resources for research of specific areas. As part of the public administration, entities are under excessive rules and regulations, either in Brazil or in the United Kingdom, as shown by some researches (Andrews et Boyne, 2014).

In addition to legal enforcement, public expenditure control is necessary for a proper allocation of key resources in areas of the Brazilian government (Araújo, 2011). In Brazil, all spent conducted by the Public Administration needs to be approved by the legislature through an annual budget law.

Beyond control, it is necessary to analyze the quality of public spending. Therefore, institutions need to know the costs of their activities. Among the various methods of costing international public universities have adopted $A B C$ (activity-based costing) (European University Association, 2008).

Before implementing a costing system in any organization, it is necessary to know and organize all processes and activities. The allocation of costs in areas with different products or services may lead the manager to a decision based on false information.

The present study aims to show the importance of understanding and the model of the business processes and how a business modelling tool can help to build a costing system model for public universities.

A case study was used to allow an exemplification of the processes to be modelled. Therefore, at the Federal Institute of Education, Science and Technology of São Paulo, we sought to understand bureaucratic complexity to the development of a costing system applied to public universities.

We use in this paper the BPMN (Business Process Management Notation) to be the language adopted by the OMG (Object Management Group) as the standard language of business process modeling and adopted by many analysts (Recker, 2010).

This article is structured into 4 parts: Section 2 provides a literature review. Section 3 provides an overview of the methodology. Section 4 provide a modeling business processes and it establishes the requirements that were presented by the Dean of Administration for notation and the tool used to define business processes and presents an analysis for solutions to be implemented for the development of a costing system. Finally, Section 5 summarizes the work presented and draws some conclusions about its development.

\section{LITERATURE REVIEW}

Activity-Based Costing ( $A B C$ ) is a costing system developed in 1988 by Robin Cooper et Robert Kaplan, in order to allocate indirect costs to objects through cost drivers. It highlights three rules for their use. First, the concentration of expensive resources. Second, the emphasis on resources whose consumption varies significantly by product and type of product. Third, the concentration resources whose demand patterns are uncorrelated with traditional measures of hand direct manpower allocation, with the material processing time (Kaplan et Cooper, 1998).

Kaplan et Cooper (1998) define the activity-based costing as an economic map of the expenses and the organization's profitability based on organizational activities. This costing system offers companies an economic map of its operation showing the existing and the projected cost of activities and business processes that, in turn, explains the cost and profitability of each product, service, and customer operation.

Cropper et Cook (2000) conducted a study on the implementation of the costing system based on activities in UK universities in the second half of the 1990's and concluded that the deployment occurred in a slow, even with pressure from donors and government.

The implementation of $A B C$ involves time and resources. It requires organizational changes and employee acceptance. It also requires investments in information technology and materials for data collection. Even with all the human, material and physical implantation it does not guarantee satisfactory results in the short term (Roztocki et al., 2004).

There is a conceptual proposal for use of $A B C$ and its variation ABM (activity-based management), explained in the hexagon below, in order to improve decision-making operations.

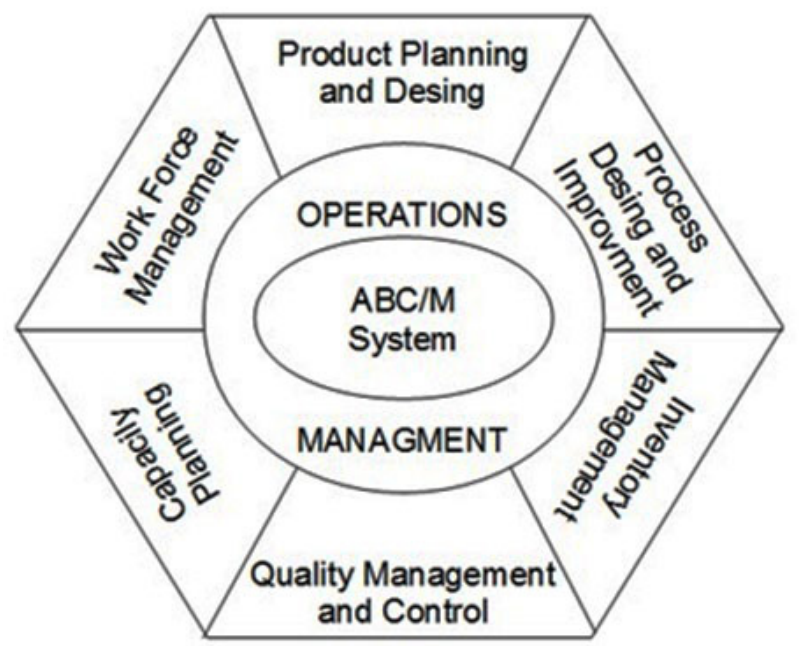

Figure 1. Operations hexagon

Source: Compiled from Gupta et Galloway (2003) 
Brazilian Journal of Operations \& Production Management Volume 13, Número 3, 2016, pp. 244-251

DOI: 10.14488/BJOPM.2016.v13.n3.a2
$A B M$ is the way in which an entity can drive, measure and control the aim to improve their performance. Therefore, the creation and use of a performance assessment framework based on activities as the primary means of resource management, continuous improvement and decisionmaking is necessary (Evans et Ashworth, 1995).

In surveys conducted by Kaplan et Anderson (2007) on the implementation of $A B C$, were noted the following problems:

- The processes of interviews and survey were slow and expensive.

- The data were subjective and difficult to validate.

- The data were expensive to store, process and report.

- Most deployments were local and not provide an integrated view of profit opportunities across the enterprise.

- It could not be easily updated to adapt to new circumstances.

- The model was theoretically incorrect when it ignored the potential of unused capacity.

TDABC simplifies the costing process, eliminating the need to interview employees and search for cost allocation of resources to activities before allocating them to cost objects (applications, products and customers). The new model assigns resource costs directly to the cost objects, using an elegant structure that requires only two sets of estimates, none of which is difficult to obtain (Kaplan et Anderson, 2007).

In a literature review were identified thirty-six empirical contributions using TDABC over the period 2004-2012. This costing method was applied in logistics, manufacturing, services, healthcare, hospitality and services nonprofit with potential benefits (Siguenza-Guzman et al.,2013) and university libraries (Pernot et al., 2007; Siguenza-Guzman et al., 2014). There are also applications in private schools (Yilmaz et al., 2013). This shows the concern in offering products or services with quality and fair prices.

The companies need to know their business processes, whatever the model they decided to apply. In this context, Business Process Management (BPM) can assist in the process knowledge and documentation of all processes, activities and procedures of the organization.

BPM has two main intellectual antecedents. The first is Deming (1952) et Shewhart's research (1986) on statistical process control. There are also the precursor of Six Sigma, improving and managements of processes. The second antecedent is the concept of reengineering business processes (Hammer, 1990; Hammer et Champy, 1993), which has positive and negative points, but interdependent.
BPM is a management discipline that integrates strategies and objectives of an organization with customer expectations and needs, by focusing on processes, end to end. This methodology encompasses strategies, objectives, culture, organizational structures, roles, policies, methods and technologies to analyze, design, implement, manage performance, process and establish governance processes (ABPMP, 2013).

A process model is a visual representation of the sequential flow and logic control of a set of activities or related actions. The process modeling is used to obtain a graphical representation of a current and/or future process within an organization (IIBA, 2009). The business analysis is a precondition for information systems design and development, in order that it can reduce the amount of problems of misunderstanding between the business areas and the IT team. The Business Analysis Body of Knowledge (BABoK) presents many techniques to understand business needs, business requirements elicitation and business process modeling (IIBA, 2009).

There are several languages notation for modeling process: BPMN, Flowchart, EPC (Event-driven Process Chain), UML (Unified Modeling Language), IDEF (Integrated Definition Language) and VSM (Value Stream Mapping).

BPMN is a standard diagramming business process created by the BPMI (Business Process Management Initiative), which was later incorporated into the OMG, a group that sets standards for information systems. This notation presents a set of symbols for modeling BPD (Business Process Diagram) of different aspects of business processes. As in most of ratings, the symbols describe clearly defined relationships, such as activity flow and order of precedence.

BPEL (Business Process Execution Language) is a workflow-oriented composition model that brings a central piece in the heavily modularized SOC (Service-Oriented Computing) model (Khoshkbarforoushha et al., 2014). The origins of BPEL come from the WSFL (Web Services Flow Language) and XLANG, IBM and Microsoft respectively. It is serialized into XML and points to a schedule following the programming approach on a large scale.

BPMN has been used lately as it offers advantages over other forms of business process modeling. Modeling is the set of activities involved in creating representations of business processes. The purpose of modeling is to create a representation of the complete way process and needs of its operation (ABPMP, 2013). BPMN is a language that facilitates communication between the organization and its stakeholders.

BPMN, for example, successfully helps in mapping business processes (Torres et al., 2011) because the layout combines other elements like actors, events and results. It 
can be used for modeling, from simple processes such as in complex processes for any type of organization.

For García-Dominguez et al. (2012) BPMN must be used for approval of detailed designs. It should be used in repetitive and process with little variation as well as the activity description. In their study, they concluded that the layout cannot model existing objects and their transitions. However, when an agility and iteration in the process design is required, suggest the use of Value Stream Mapping (VSM). This tool was designed to identify problems and also to improve to create plans for waste reduction.

Giuseppe et al. (2014) studied a way to manage the risk of deviations of the "Conformance risk aware design" process. Not always what was expected or planned corresponds to the reality. A Business Analyst should mediate this problem.

\section{METHODOLOGY}

The research method uses a case study approach combined with Business Analysis techniques from BABoK to model the business process for information system design.

This paper aims to show the complexity of the bidding process in public service to purchase goods and services. We use through business process modeling technique by BPMN notation. Through knowledge of the process it can be reconfigured to optimize human, material and financial resources. This will calculate the cost of idleness and implementation of TDABC.

The case study approach, defined by Yin (2014) as a research strategy that seeks to examine, in deep, a phenomenon within its context, to identify the business needs related to the costing process.
We collected a data set due to observation, interviews with employees and analysis of internal documents of the organization to understand the process context. The documental analysis was based on material provided by the institution, through management reports, institutional development plan, as well as information available on the Federal Institute of Education, Science and Technology of São Paulo (IFSP) website. It was possible to expose in details the current flow mapped process. However, research in loco revealed some changes in the bidding flow of the studied institution.

To model the organizational processes of the IFSP we used the Yaoquiang BPMN Editor 4.0 software, as it was more appropriate, as it performs a real-time consistency check during the BPMN 2.0 modeling (Geiger et al. 2013).

\section{RESULTS}

Two cases were mapped in this article that will be part of the costing model to be developed for the IFSP: the requisition of materials and the process of acquisition of fixed assets and inputs.

The first, requisition of materials, shown in Figure 2, starts the need for inputs to the institution activities.

For the activities carried out in laboratories, library, classrooms and office specific cost centers will be created because they generate quantifiable services. As for the support activities can be created a single cost center, which will be discussed at future meetings.

The International Federation of Accountants defines inventory accounting through the International Public Sector Accounting Standards Board No. 12. This standard addresses

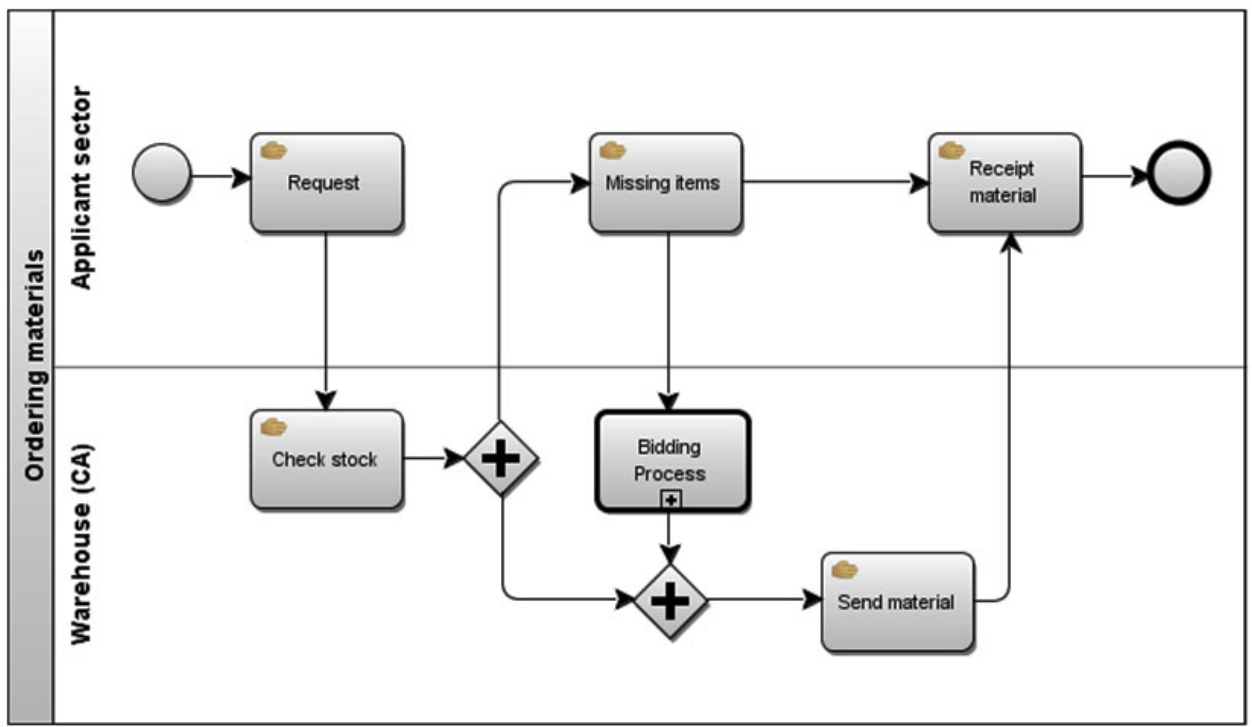

Figure 2. Procedure material requisition Source: The authors own. 


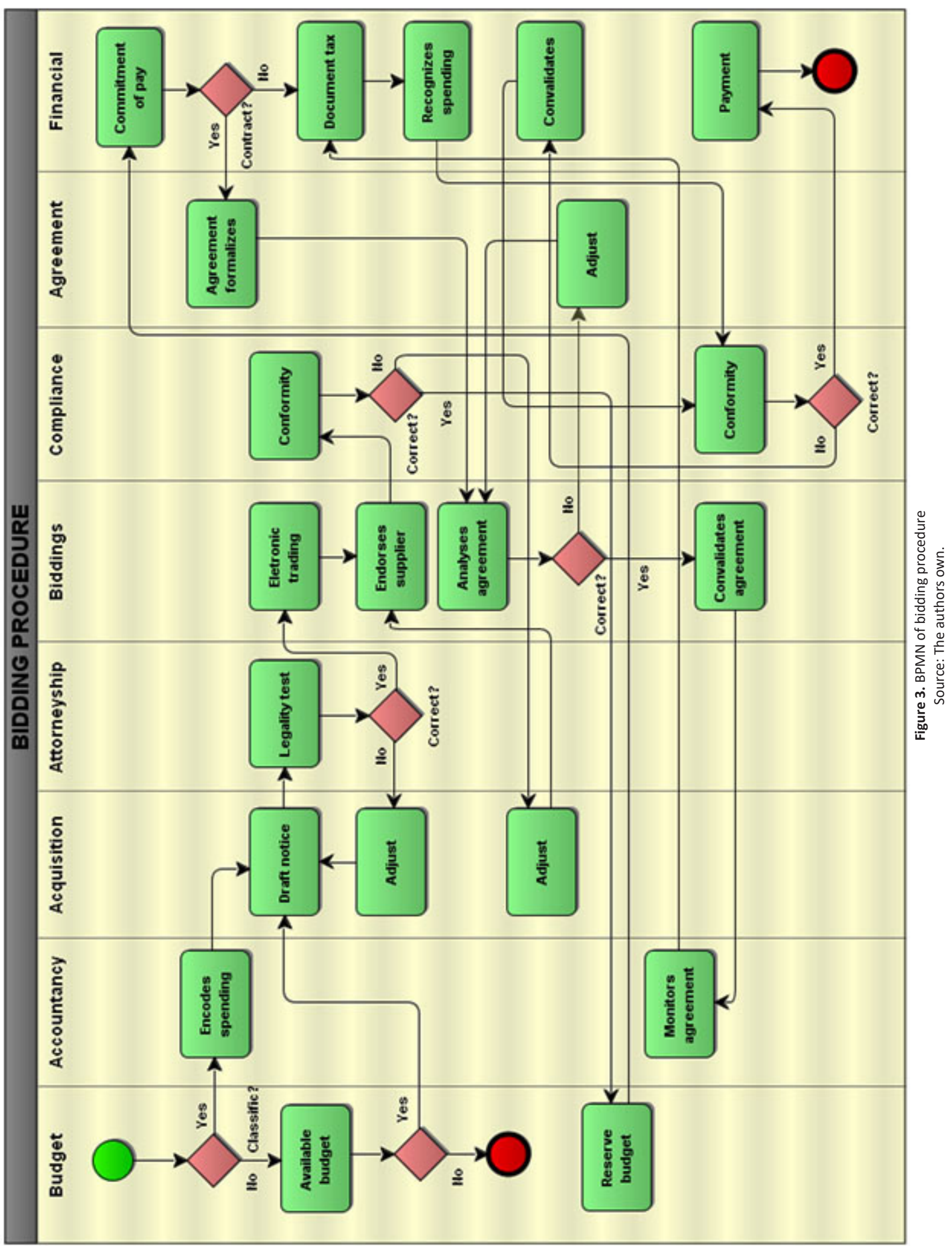


the recognition or not of the expenses involved in the acquisition and processing costs, the result of the entities. In the system under development will be considered as cost materials consumed.

All Brazilian Public Administration entities are required by law to conduct bidding. This requirement comes from the Federal Law No. 8666, known as the law of tenders and contracts and Law No. 10,520, which introduced another form of bidding, the trading session.

To carry out any spending in the public sector is still necessary, the approval by the Legislature, materialized in an annual budget law. It is estimated revenues and fixed expenses for the following year.

A simple process of purchasing goods and services demand activities of eight different sectors in this organization. A bureaucratic process is required to make the payment to the supplier or service provider, extinguishing the financial obligation. BPMN is helpful, because it showed versatility to model the different situations of the acquisition of goods and services. These model applications generate BPMS (Business Process Management Systems). They has allowed a proper programming of the costing system.

It was analyzed the convenience and the opportunity of purchasing a physical or a service, introducing yourself a bidding process, following the steps of the Figure 3 diagram:

The process of acquisition of goods and services was modeled. From this point on, it was used at least seventeen employees. Each acquisition has a handheld unit cost of direct work of two hundred thirty-nine dollars in 2014. Table 1 shows the costs of each activity and the time spent, we ask in interviews, and salary queries:

Table 1. Direct labor cost Source: The authors own.

\begin{tabular}{|c|c|c|c|c|c|}
\hline Area & Resources & Unitary cost / $h$ & Activity & $\begin{array}{l}\text { Spending time } \\
\text { (h) }\end{array}$ & Total USD \\
\hline \multirow[t]{2}{*}{ Budget } & Worker 1 & 12.91 & Available budget & 1.0 & 12.91 \\
\hline & Worker 2 & 6.51 & Reserve budget & 1.0 & 6.51 \\
\hline \multirow[t]{2}{*}{ Accountancy } & Worker 1 & 7.55 & Encodes spending & 0.5 & 3.78 \\
\hline & Worker 2 & 14.21 & Monitors agreement & 0.5 & 7.10 \\
\hline Acquisition & Worker 1 & 8.86 & Draft notice & 1.0 & 8.86 \\
\hline Attorneyship & Worker 1 & 51.76 & Legality test & 1.0 & 51.76 \\
\hline \multirow[t]{4}{*}{ Biddings } & Worker 1 & 12.91 & Eletronic trading & 8.0 & 103.29 \\
\hline & Worker 2 & 6.01 & Endorses supplier & 0.5 & 3.00 \\
\hline & Worker 3 & 7.31 & Analyses agreement & 0.5 & 3.66 \\
\hline & Worker 4 & 6.51 & Convalidates agreement & 0.5 & 3.25 \\
\hline Compliance & Worker 1 & 9.50 & Conformity & 1.5 & 14.24 \\
\hline Agreement & Worker 1 & 8.86 & Agreement formalizes & 1.0 & 8.86 \\
\hline \multirow[t]{5}{*}{ Financial } & Worker 1 & 5.81 & Commitment of pay & 0.4 & 2.32 \\
\hline & Worker 2 & 6.97 & Document tax & 0.2 & 1.39 \\
\hline & Worker 3 & 6.97 & Recognizes spending & 0.3 & 2.09 \\
\hline & Worker 4 & 7.55 & Convalidates & 0.4 & 3.02 \\
\hline & Worker 5 & 14.21 & Payment & 0.2 & 2.84 \\
\hline Total & 17 & - & - & 18.5 & 238.89 \\
\hline
\end{tabular}

Due to the bureaucratic process, we make the payment to the supplier or service provider, extinguishing the financial obligation.

\section{CONCLUSION}

For both public and private $\mathrm{HEI}$, resources are necessary to acquire efficiency. Therefore, they need to know their costs.
The article has shown the importance of understanding the business processes for building a cost model for public universities. Therefore, we conducted a case study on the IFSP, where BPMN methodology was conducted to model their processes. TDABC is presented as a new form of funding, and more simplified applications in relation to $A B C$. Currently, we studied the reduction of waste, either of resources or time. 
In the analyzed case, a simple process of acquisition materials and services demand activities of eight different sectors. These factors are mainly due to internal rules and legal regulations. To know details of each of the processes of any organization is necessary to map them. Therefore, BPMN is a notation easy to understand. The contribution of this study is to present a business process modeling to optimize time and resources applied to public services. This research has the limiting factor some variations in bidding flow of the studied institution. As a future work it will be continued in the definition of the systems requirements to perform the development of a costing software for HEI.

\section{ACKNOWLEDGEMENTS}

The authors gratefully acknowledge the support of Federal Institute of Education, Science and Technology of São Paulo (IFSP - Instituto Federal de Educação, Ciência e Tecnologia de São Paulo) and Higher Education Personnel Improvement Coordination (CAPES - Coordenação de Aperfeiçoamento de Pessoal de Nível Superior).

\section{REFERENCES}

ABPMP (2013), BPM CBOK V3.0: Guide to business process management body of knowledge - Commom body of knowledge. 1st ed. Association of Business Process Management Professionals (ABPMP), Saint Paul, MN.

Andrews, R., et Boyne, G. A. (2014), "Task Complexity, Organization Size, and Administrative Intensity: The Case of UK Universities", Public Administration, Vol. 92 No. 3, pp. 656-672.

Araújo, M. B. (2011) "A contabilidade de custos como instrumento de gestão no setor público" Conjuntura \& Planejamento, Vol. 1 No. 170, pp. 42-49.

Cropper, P., et Cook, R. (2000), "Activity-Based Costing in Universities-Five Years On", Public Money and Management Vol. 20 No. 2, pp. 61-68.

Deming, W. E. (1952), Elementary principles of the statistical control of quality: a series of lectures, 2nd ed. Nippon Kagaku Gijutsu Remmei, Tokyo, TYO.

European University Association (2008), Financially Sustainable Universities: Towards full costing in European universities (Working Paper). 1st ed. EUA Publications 2008, Belgium.

Evans, H., et Ashworth, G. (1995), "Activity-based management: moving beyond adolescence", Management Accounting-London, Vol. 73 No. 1, pp. 26-31.

García-Domínguez, A., Marcos, M., and Medina, I. (2012), "A comparison of BPMN 2.0 with other notations for manufacturing processes", Key Engineering Materials, Vol. 502, pp. 1-6.

Geiger, M., Wirtz, G., and der Weberei, A. (2013), “BPMN 2.0 Serialization-Standard Compliance Issues and Evaluation of Modeling Tools", In EMISA pp. 177-190.

Giuseppe, C., Valerio, M., Teresa, M., and Carmela, S. L. (2014), "A Simulation Approach in Process Mining Conformance Analysis", The Introduction of a Brand New BPMN Element. IERI Procedia, Vol. 6 No. 1, pp. 45-51.

Gupta, M., et Galloway, K. (2003), "Activity-based costing/management and its implications for operations management", Technovation, Vol. 23 No. 2, pp. 131-138.

Hammer, M. (1990) “Reengineering work: don't automate, obliterate", Harvard business review, Vol. 68 No. 4, pp. 104-112.

Hammer, M., et Champy, J. (1993), "Reengineering the corporation: A manifesto for business revolution", Business Horizons, Vol. 36 No. 5, pp. 90-91.

IIBA (2009), A guide to the business analysis body of knowledge (BABOK ${ }^{\oplus}$ guide) Version 2.0. 1st ed. International Institute of Business Analysis (IIBA), Whitby, ON.

Kaplan, R. S., et Anderson, S. R. (2007), Time-Driven Activity-Based Costing: A Simpler and More Powerful Path to Higher Profits. 1st ed. Harvard Business School Press, Cambridge, MA.

Kaplan, R. S., et Cooper, R. (1998), Cost and effect: using integrated cost systems to drive profitability and performance. 1st ed. Harvard Business School Press, Cambridge, MA.

Khoshkbarforoushha, A., Jamshidi, P., Gholami, M. F., Wang, L., and Ranjan, R. (2014), "Metrics for BPEL Process Reusability Analysis in a Workflow System", Systems Journal IEEE, Vol. PP No. 99, pp. 1-10.

Pernot, E., Roodhooft, F., and Van den Abbeele, A. (2007), "Time-Driven Activity-Based Costing for Inter-Library Services: A Case Study in a University". The Journal of Academic Librarianship, Vol. 33 No. 5, pp. 551-560.

Recker, J. (2010), "Opportunities and constraints: the current struggle with BPMN", Business Process Management Journal, Vol. 16 No. 1, pp. 181-201.

Roztocki, N., Porter, J. D., Thomas, R. M., and Needy, K. L. (2004), "A Procedure for Smooth Implementation of Activity-Based Costing in Small Companies", Engineering Management Journal, Vol. 16 No. 4, pp. 19-27.

Shewhart, W. A. (1986), Statistical method from the viewpoint of quality control. 1st ed. Courier Dover Publications, New York, NY. 
Siguenza-Guzman, L., Van den Abbeele, A., Vandewalle, J., Verhaaren, H., and Cattrysse, D. (2013), "Recent evolutions in costing systems: A literature review of Time-Driven Activity-Based Costing", Review of Business and Economic Literature, Vol. 58 No. 1, pp. 34-64.

Siguenza-Guzman, L., Van den Abbeele, A., Vandewalle, J., Verhaaren, H., and Cattrysse, D. (2014), "Using Time-Driven Activity-Based Costing to support library management decisions: A case study for lending and returning processes", The Library, Vol. 84 No. 1, pp. 1-23.

Torres, V., Giner, P., Bonet, B., and Pelechano, V. (2010), Adapting BPMN to Public Administration, in: Business Process Modeling Notation. Springer-Verlag Berlin Heidelberg, pp. 114-120.

Yilmaz, M., Coskun, A., and Yilmaz, S. (2013), "A Comparison and an Implementation of Time Driven Activity Based Costing and Activity Based Costing Methods in Private Schools", in: International Conference on Economic and Social Studies, 10-11 May, 2013, Sarajevo. Vol. 1 No. 1, International Burch University.

Yin, R. K. (2014), Case study research: design and methods, 5th ed. Sage Publications, Thousand Oaks, CA. 